\author{
Military Technical College \\ Kobry El-Kobbah, \\ Cairo, Egypt
}

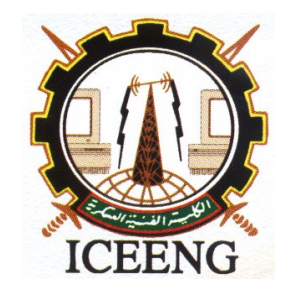

\author{
$7^{\text {th }}$ International Conference \\ on Electrical Engineering \\ ICEENG 2010
}

\title{
Enhancing the Performance of the Marine and Tidal Current Converters Using DC-DC Boost Converter
}

\author{
By \\ Salah M. Kamel * \\ Emad M. Ahmed** \\ Noriyuki Hayashi** \\ Masahito Shoyama**
}

\section{Abstract:}

Due to highly demand on the renewable energy sources as a free and a clean power resource, extracting energy from unsteady flow using marine and tidal current turbines has a special focusing nowadays. For their resource characteristic, extracting energy from them needs more simple and robust converter in order to avoid the drawbacks of the mechanical system such as gearbox and makes the marine/tidal current energy more reliable. The required AC-DC-AC conversion system equipped with DC-DC boost converter has been designed. To investigate the efficient performance of that conversion system especially at low current speed, different operating conditions were studied; the system was tested with/without boost converter at different current speeds operation. Moreover, the effect of including boost converter on the total harmonic distortion THD is checked.

\section{Keywords:}

Renewable energy, Marine and tidal current converter, DC-DC boost converter

* Faculty of Engineering, South Valley University, Egypt

** Faculty of Information Science and Electrical Engineering, Kyushu University, Japan 


\section{Introduction:}

Free flow marine currents i.e. unregulated water courses, tides, and other ocean currents, are energy resources yet to be utilized in the commercial scale. This non fossil source can give an environmentally great contribution to the world electricity production [1]. A number of projects around the world involved in extracting energy from these resources exist and most concepts are similar to wind energy converters in that they include a turbine, generator, and a power electronic interface to feed an isolated load or integrated with the grid $[2,3]$.

Wind power is similar to marine/tidal current energy as they considered with harnessing the kinetic energy in a flowing fluid. However, there are also a number of significant differences, such as in the wind energy the difference between cut in and the cut off speed reaches about 10-15 m/s so a maximum power point tracker (MPPT) and hence a gear box are needed to pick the maximum power of the intercepted wave. In the other way, the marine current converter faces more difficult problem that most parts of the system will be submerged in the water and thus not easily accessible, so it is good to avoid mechanical complex systems (such as gearboxes) by using generators suitable for variable speed and load operation [1]. Although the use of the induction generators (IG) are a commonly choice used in the field of renewable energy especially in the wind energy [4], but the main drawback of these generators is their operation at higher speed and not available at lower speed as in the case of marine /tidal current converters. Consequently, it needs a gearbox to accelerate the induction generators. Moreover, it is concluded in [5] that up to $20 \%$ of the downtime for a wind power plant is due to gearbox failures, and that the majority of these failures are due to wears. Therefore, avoiding gearboxes, yawing and blade pitching are Likely to be beneficial for system reliability, but require certain adaptation for the rest of the system. So the other substitution of the induction generators in marine and tidal energy converters is synchronous generator (SG). Synchronous machines tend to have a large number of poles especial in the salient pole type i.e. it is available at low speeds about $10 \mathrm{rpm}$ [1]. Marine/tidal current turbine generator usually supplies an AC voltage lower than the grid voltage and frequency, and their output voltage varies in a wide range according to various operation conditions. Some boosting techniques are needed to boost the output DC voltage supplied by the rectifier system then invert it into an AC voltage with the desired voltage and frequency $[6,7]$.

In this paper enhancing the performance of AC-DC-AC conversion system by including a boost DC-DC converter has been studied. Also, the performance of such conversion system is checked at different current speeds and loading conditions using MATLAB simulation with SimPowerSystems toolbox. 


\section{System Description}

\section{A. Power Generation System.}

The studied system is composed of a marine current turbine, a PMSG, and a back-toback three phase converter contains a DC-DC boost converter as shown in Fig. 1. This system can feed either an isolated load or a strong electrical grid. However, in this paper a special concentration to feed an isolated load with regulated voltage and frequency is done. This is the status for the off shore marine/tidal current turbines or when there is no availability to connect the grid. All the marine current converter stages were implemented on the Matlab SimPowerSystems toolbox to check the system response when there are some undesirable conditions such as increasing or decreasing of the marine/ tidal current speeds.

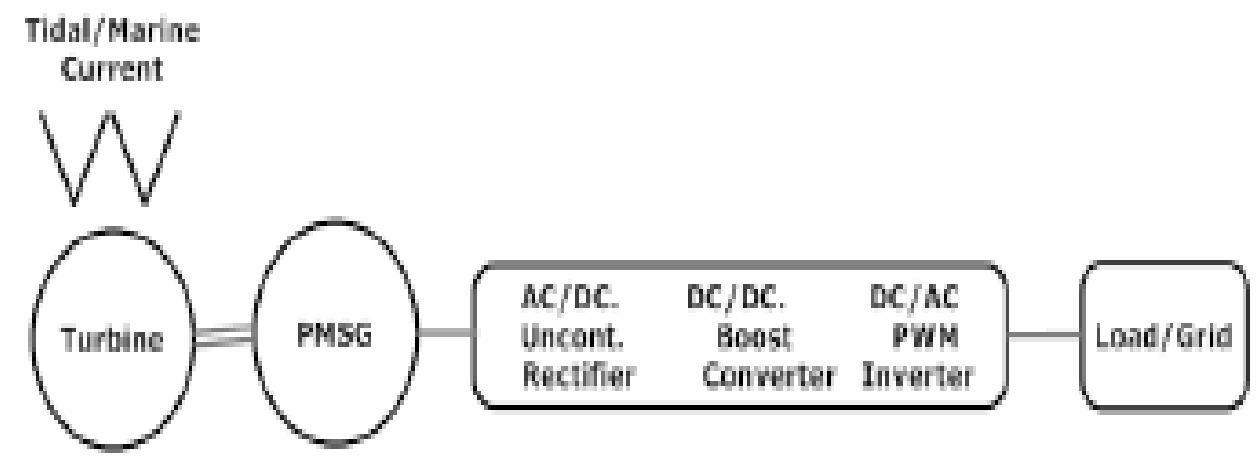

Figure (1): Schematic diagram of the Marine/Tidal current conversion system

\section{B. Turbine Model}

For the marine and tidal current turbine modeling, the expression of the extractible power $\mathrm{Pt}$, in function of the water flow speed and turbine parameters is

$$
P_{t}=\frac{1}{2} \rho C_{P} S w^{3}
$$

Where $\rho$ is the water density, $C_{p}$ is the non-dimensional power coefficient (expressing the turbine efficiency), $S$ is the surface swept area by the turbine blades, and $w$ is the water flow speed. The surface area $\mathrm{S}$ is defined as

$$
S=2 R_{t} H_{t}
$$


Where $R_{t}$ is the turbine radius and $H_{t}$ is the turbine height [8]. To simulate the variation of the marine/tidal current speed, a complete model for the turbine is not included, but it is simulated as prim mover with different speeds

\section{Control Strategy}

In order to control the frequency and the load voltage as the current speed changes, the architecture of the designed control system is shown in Fig. 2. The control strategy can be separated into two main operations:

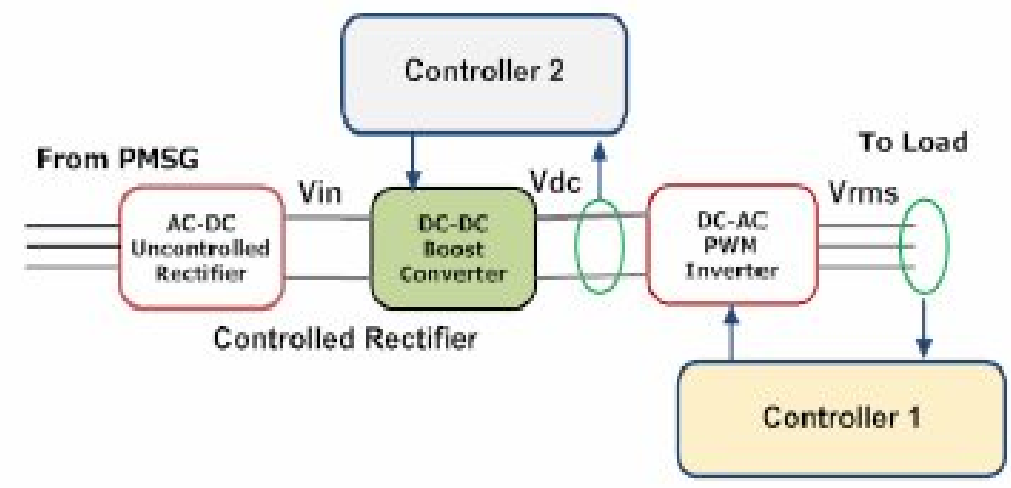

Figure (2): Architecture of the $A C-D C$-AC Converter

\section{$\underline{\text { A. Controlled Rectifier }}$}

This rectifier containing an uncontrolled bridge rectifier (diodes rectifier) followed by a boost DC-DC converter. An equivalent circuit of the boost converter is shown in Fig. 3. The steady state input/output relationship for the boost converter in the continuous conduction mode $(\mathrm{CCM})$ is

$$
\frac{V_{d c}}{V_{\text {in }}}=\frac{1}{1-D} \quad 0 \leq D \leq 1
$$

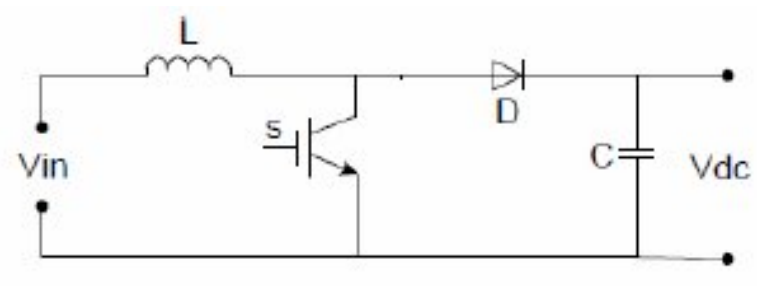

Figure (3): DC-DC Boost Converter 
Where $D$ is the converter duty cycle. $V_{i n}$ is the rectified DC voltage, and $V_{d c}$ is the inverter input dc voltage. The role of the Boost DC-DC converter is in charge to regulate and maintain the inverter DC input voltage to a suitable value that allows the inverter to transform this DC voltage to the desired load voltage and the frequency. This can be done by the Controller 2, which responsible to control the boost converter duty cycle using a feedback control loop occupied with a PI controller that will drive the PWM driver, as shown in Fig. 4.

To avoid the mal-operation of the DC-DC boost converter, the discontinuous conduction mode (DCM) of it should be avoided. This can be done by designing the elements of the DC filter (composed of L and C) as in (4) and (5) $[9,10]$.

$$
\begin{aligned}
& L \geq L_{b}=\frac{(1-D)^{2} D R}{2 f} \\
& C \geq C_{\text {min }}=\frac{D V_{d c}}{V_{r} R f}
\end{aligned}
$$

Where $f$ is the switching frequency, $V_{d c}$ is inverter input dc voltage, $V_{r}$ is the voltage ripple in the inverter input voltage, and $R$ is the equivalent load resistance seen by the boost converter that can be computed from (6),

$$
V_{d c} I_{d c}=V_{d c}^{2} / R=\operatorname{Re}\left(\sqrt{3} V_{a c} I_{a c}{ }^{*}\right)
$$

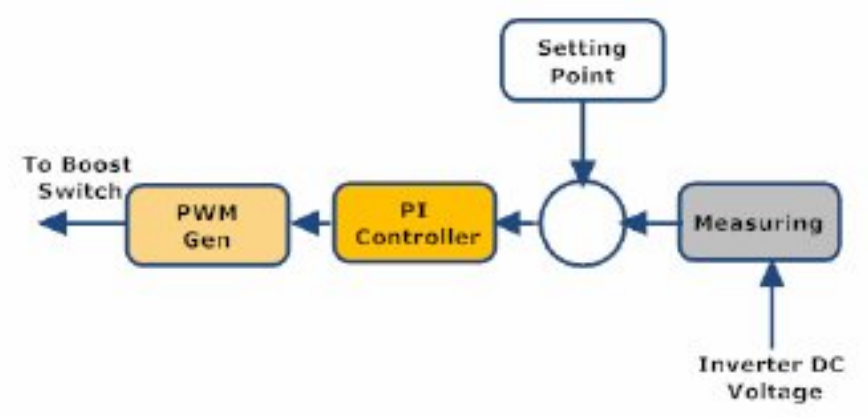

Figure (4): Schematic diagram of Controller 2

\section{B. Load Side Inverter (PWM)}

The load side inverter is in charge to control the voltage and the frequency of the load; these can be done using PWM driver. The different stages of the Controller 1 are implemented in Fig. 5. 
After transforming the three phases load voltage into dq0 reference frames with the help of the phase lock loop (PLL) at $50 \mathrm{~Hz}$, these components are compared with the setting points, then the $P I$ controller will generate the direct axis modulation index, and the quadrature axis modulation index $\left(m_{d}, m_{q}\right)$. To avoid the saturation of the inverter (square wave mode), the modulation indices should satisfy (7). The root mean square of the load voltage can be computed from (8).

$$
\begin{aligned}
m_{a} & =\sqrt{m_{d}{ }^{2}+m_{q}{ }^{2}} \leq 1 \\
V_{r m s} & =\frac{\sqrt{3}}{2 \sqrt{2}} m_{a} V_{d c}
\end{aligned}
$$

Where $m_{a}$ is the amplitude modulation index,

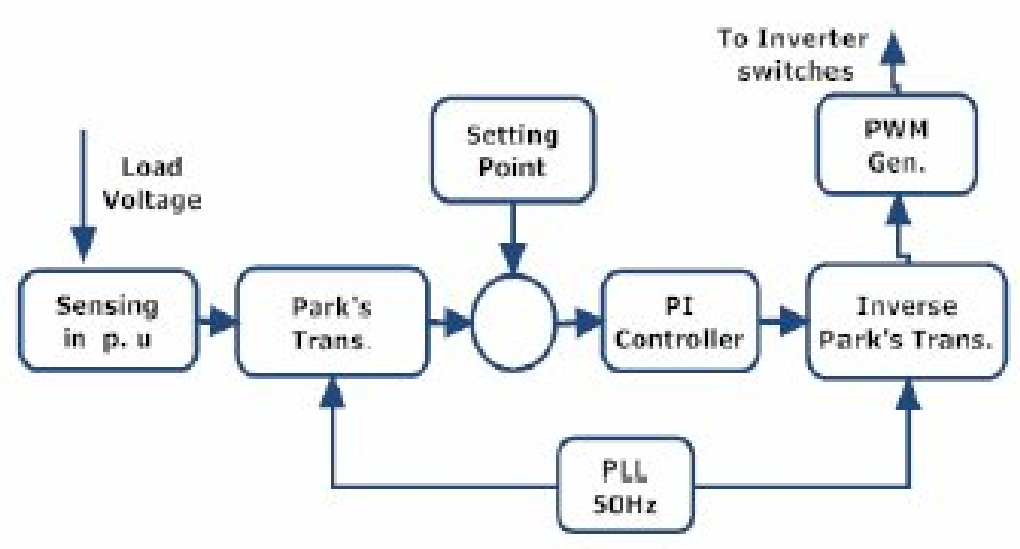

Figure (5) Schematic diagram of Controller 1

\section{Simulation Model}

In order to present the importance of including the DC-DC boost converter to the ACDC-AC conversion system, a numerical simulation in MATLAB/SimPowerSystems environment has been done. The simulated model consists of a PMSG, a three phase uncontrolled rectifier, a DC-DC boost converter, a three phase PWM inverter, and a LC filter. This model used to feed three phase resistive load as shown in Fig. 6. The detailed system parameters are included in the appendix. The variation of the current speed is simulated as a step change in the generator speed (generator revolution per minute). Since the marine and tidal current has low current speed $(0-2 \mathrm{~m} / \mathrm{s})$ with respect to wind 
energy, the performance of the conversion system has been tested at low revolution speed $(25 \mathrm{rpm})$.

\section{Simulation Results}

Figure 7a shows the performance of the AC-DC-AC conversion system with and without the DC-DC boost converter. It has been noticed that the conversion system with the boost converter can regulate the output voltage over the load at low current speed (low generator speed). However, the conversion system without boost converter can't regulate the voltage over that load, which is due to the lower value of the inverter input $\mathrm{dc}$ voltage. Fig. $7 \mathrm{~b}$ presents the variation of the modulation index to generate the required load voltage. In the case with the boost converter, the desired value of the modulation index to generate the required load voltage is lower the other case.

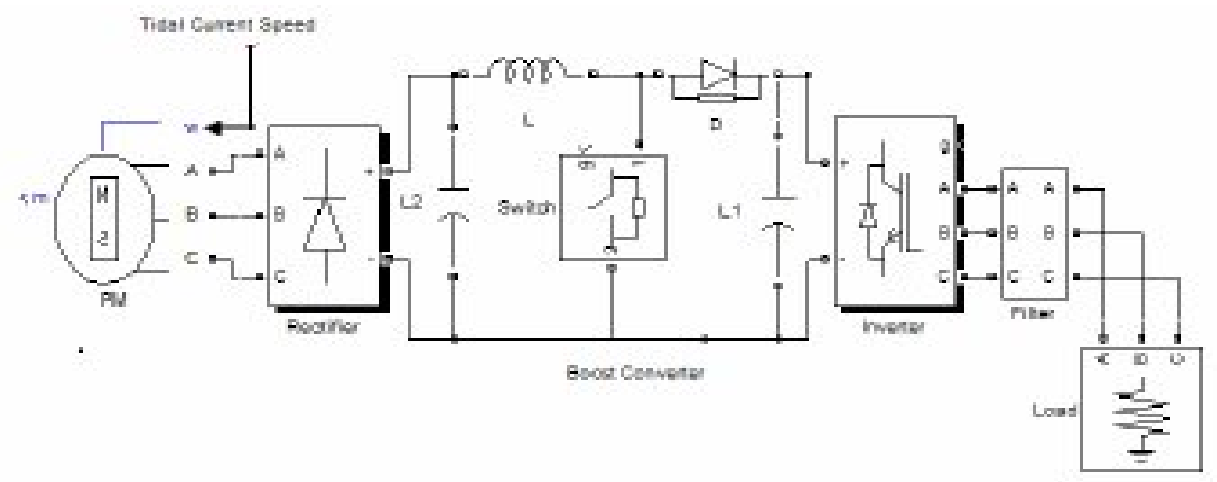

Figure (6): Matlab simulation model, showing the PM generator, uncontrolled rectifier, DC-DC boost converter, PWM inverter, LC filter, and three phase resistive load.

Figures $8 \mathrm{a}, 8 \mathrm{~b}$ show that, as the generator speed doubled (from $25 \mathrm{rpm}$ to $0 \mathrm{rpm}$ ), the performance of the AC-DC-AC conversion system with and without the DC-DC boost converter is nearly close to each other in the steady state.

As a simulation of the real situation in the tidal current speed, the revolution speed of the generator will be changed as shown in Fig. 9a. The performance of the conversion system is shown in Fig.9b. The effect of adding the boost converter is clear; as the generator speed changes the boost converter enables the conversion system to fed the load with nearly constant voltage and frequency. However without the boost DC-DC converter, the conversion system can not regulate the voltage over the load. Moreover, the conversion system without the boost DC-DC converter enters the saturation mode $(\mathrm{ma}=1)$, which is shown in Fig. 10 
The effect of including the boost converter on the amount of the harmonic content also has been examined. Fig. 11 shows the total harmonic distortion as the speed varied from $25 \mathrm{rpm}$ to $40 \mathrm{rpm}$.

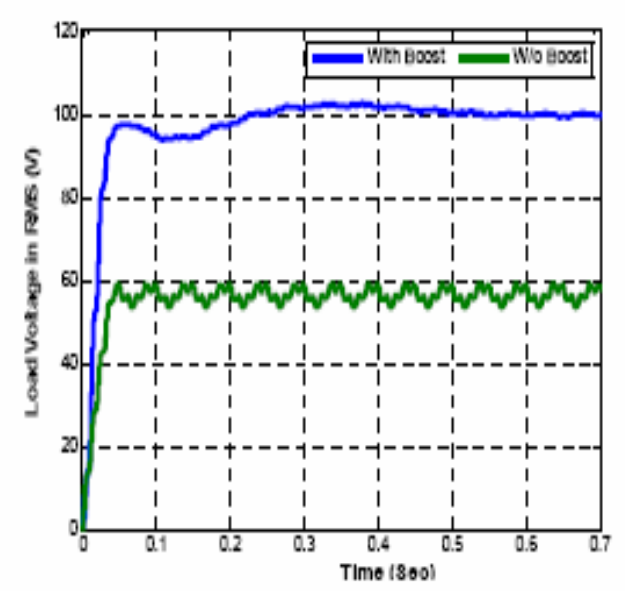

(a)

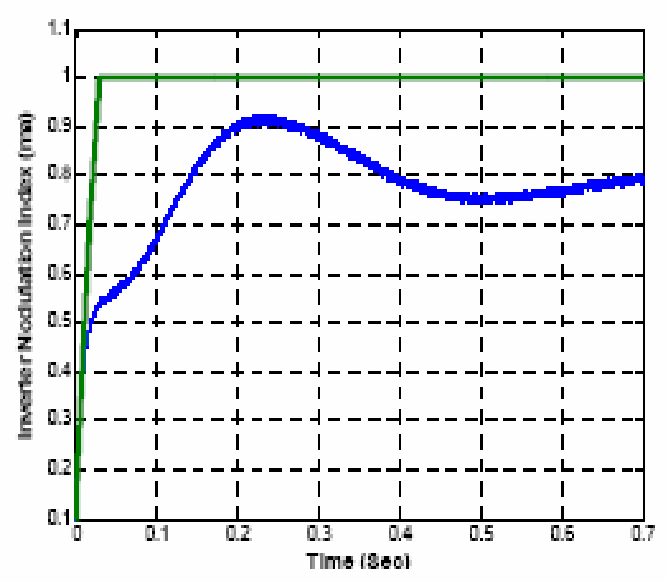

(b)

Figure (7): Conversion system performance at current speed $25 \mathrm{rpm}$ a) Load Voltage (rms)

b) Inverter modulation index

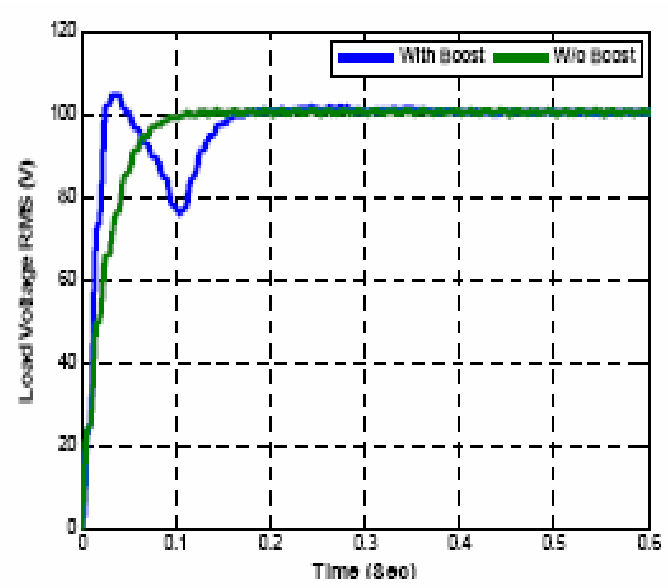

(a)

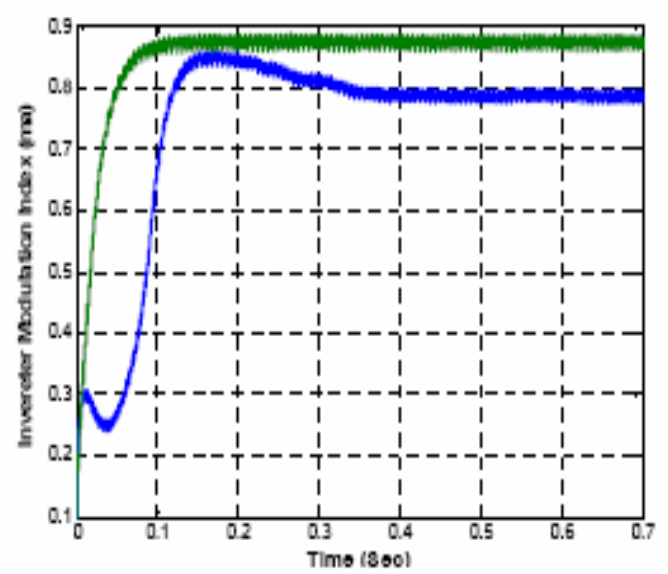

(b)

Figure (8) Conversion system performance at double current speed a) Load Voltage (rms) b) Inverter modulation index

From these results, we can conclude that with the DC-DC boost converter the conversion system will be able to harness the marine and tidal current energy in low as well as in the high current speed without any problem or in another meaning, the cut in 
speed $\left(C_{i n}\right)$ for generating the electrical power will be lower with the DC-DC boost converter than without it, i.e. this will increase the efficiency and reliability of the conversion system.

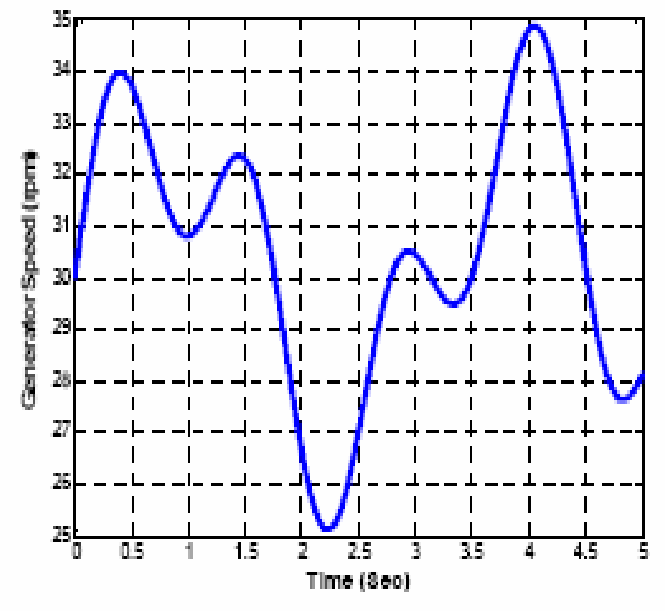

(a)

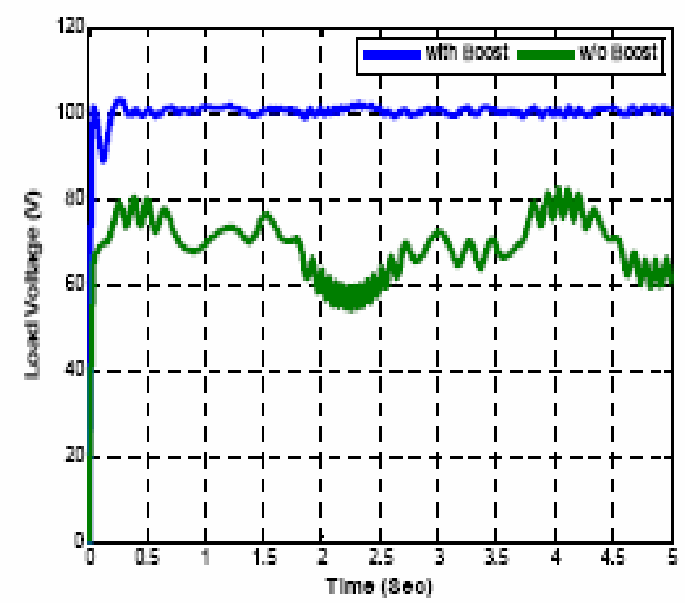

(b)

Figure (9): Conversion system performance with unsteady current speed a) Generator speed (rpm)

b) load voltage (rms)

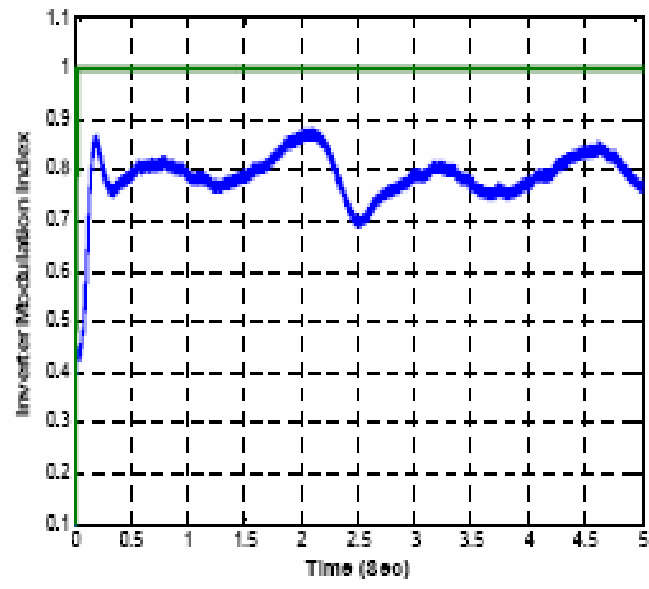

Figure (10): Inverter modulation index during unsteady current speed

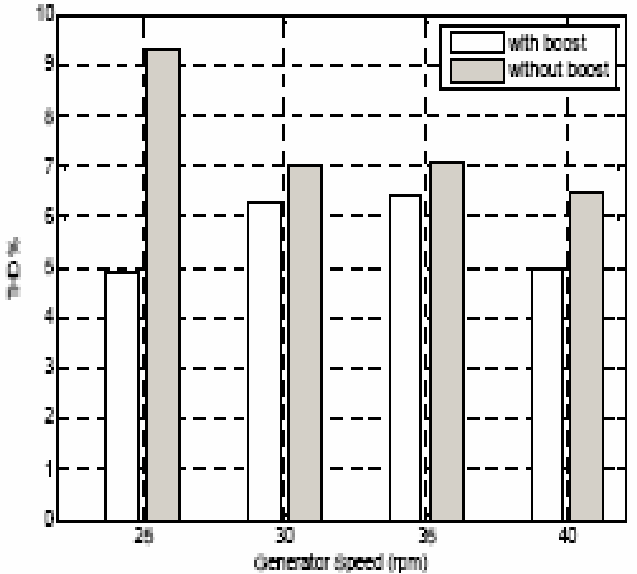

Figure (11): Load THD with generator speed

\section{Conclusion}

Including the DC-DC boost converter in the conversion system enables the PWM inverter to operate in the linear mode of the modulation index without entering 
saturation mode. The total harmonic distortion decreased as a result. Also, Including a DC-DC boost converter is mandatory in low speed operation, as in the case of marine and tidal current, especially, when it is unavailable to use gearboxes to increase the generator speed.

\section{Appendix}

PMSG: $R s=2.875, L_{s}=1.9 \mathrm{mH}$, pair poles $=16$;

DC-DC: $L=1 \mathrm{mH}, C=100 \mathrm{uF}, f_{s}=20 \mathrm{kHz}, K_{p}=0.04, K_{i}=10$;

PWM Inverter: $K_{p}=0.1, K_{i}=50$;

Load: $V_{L L}=100 \mathrm{~V}, P=300 \mathrm{~W}$;

\section{References:}

[1] K. Yuen, K. Thomas, et al," Matching a Permanent Magnet Synchronous Generator to a Fixed Pitch Vertical Axis Turbine for Marine Current Energy Conversion”, IEEE J. Ocean Eng., Vol. 34, No.1, Jan. 2009.

[2] IT Power, Seacore, et al, "Sea flow-World's first pilot project for the exploitation of marine currents at a commercial scale", EUR 21616, 2005, pp. 1-34, ISBN: 92-894-4593-9.

[3] S. E. Ben Elghali, et al, "A simulation model for the evaluation of the electrical power potential harnessed by a marine current turbine", IEEE J. Ocean Eng., Vol. 32, No. 4, pp. 786-789, Oct. 2007.

[4] J. M. Carrasco, et al, "Power Electronic Systems for the grid Integration of Renewable Energy Sources; A Survey”, IEEE, Ind. Electronic Trans., Vol. 53, No. 4, Aug. 2006.

[5] ] J. Ribrant, L. Bertling, et al, "Survey of Failures in Wind Power Systems with Focus on Swedish Wind Power Plants during 1997-2005", IEEE, Energy Conv. Trans., Vol. 22, No. 1, pp. 167-173, Mar. 2007.

[6] Y. Chen, et al, "A cost effective single stage inverter with maximum power point tracker", IEEE trans., Power Electronic, Vol. 19, No. 5, pp. 1289-1294, Sep. 2004.

[7] Yang Chen, K. Smedley, "Three- Phase Boost-Type Grid Connected Inverter", IEEE trans., Power Electronics, Vol. 23, No. 5, pp. 2301-2309, Sep 2008.

[8] A. Andeica, S. Bacha, "Micro-Hydro Water Current Turbine Control for Grid Connected or Islanding Operations", IEEE, 978-1-4244-1668-4, 2008.

[9] ] M. H. Rashid, Power Electronic Handbook, Academic press, Canada, 2001

[10] A. Jayam, et al, 'Efficiency Analysis and Comparative Study of Hard and Soft Switching DCDC Converter in a Wind Farm', IEEE, 